\title{
Research on the Impact of Technology Innovation on Quantity and Quality of Economic Growth in the Yangtze River Delta of China: A Comparative Study
}

\author{
Jialei $\mathrm{Cao}^{1,2^{*}}$, Chenran $\mathrm{Ge}^{2}$ \\ ${ }^{1}$ School of Finance, Taxation and Public Administration, Tongling University, Tongling 244000, China \\ ${ }^{2}$ Endicott College of International Studies, Woosong University, Daejeon 300718, Republic of Korea
}

Corresponding Author Email: 201980301@live.wsu.ac.kr

https://doi.org/10.18280/ijsdp.160806

Received: 9 September 2021

Accepted: 10 October 2021

\section{Keywords:}

technological innovation (TI), highquality economic growth (HQED), panel quantile regression, Yangtze River Delta (YRD)

\begin{abstract}
High-quality economic development (HQED) has recently become a crucial sustainable growth mode in China, which pursues economic growth while maintaining social equity and green ecology. The HQED of the Yangtze River Delta (YRD) has played an exemplary role in achieving the leap from "China speed" to "China Quality". In this paper, we first use the entropy-weight multidimensional comprehensive evaluation method to calculate the HQED index as a proxy for the quality of economic growth. Then, using panel data of 41 cities in the YRD, we conduct a comparative study to examine impacts of technological innovation (TI) on quantity and quality of economic growth by employing different panel estimation models over the period 2009-2019 and check the robustness in five ways. Finally, this paper investigates the TI-economic growth link based on the panel quantile regression across the conditional distributions of economic growth levels. Results show that TI has significantly positive effects in terms of both quantity and quality of economic growth, and the promoting effect on the quantity of economic growth is almost four times higher than that of quality under mean estimations by double fixed-effects. The effect on quantity of economic growth is also stronger than that of quality under the conditional distribution, and TI has a stronger impact for regions with higher levels of economic growth.
\end{abstract}

\section{INTRODUCTION}

The pursuit of economic growth is the eternal theme of all countries in the world. Therefore, the study of economic growth has been a hot topic in academy [1-4]. For developing countries, it is more important that not only focus on the quantity of economic growth, but also on the quality of economic growth to achieve sustainable growth. China's economy, especially the quantity of economic growth, has achieved remarkable improvements at the expense of enormous social and environmental costs [4]. On the one hand, the high-speed growth has resulted in various social issues, such as high unemployment rate, unbalanced medical resources, inequitable cultural sharing, and widening income gap [5]; on the other hand, the rapid economic growth has also brought about serious environmental damage, ecological imbalance, and depletion of natural resources. Therefore, it is very important for academia, governments, and individuals to maintain balance among economic growth, social equity and environmental protection. In this context, high-quality economic development (HQED) is put forward by the 19th National Congress of the Communist Party of China, indicating that economy development is urgent to achieve the leap from "Chinese speed" to "Chinese quality".

Technological innovation (TI) is an important driving force to achieve HQED and enhance the regional core competitiveness $[3,4,6,7]$. A large number of scholars have conducted a lot of research about the impact of TI on the economic growth rate, social progress, and environmental protection, separately. However, whether TI improve the HQED? What difference between the impact of TI on the quantity and quality of economic growth? Does the impact of TI differ across different levels of economic development? These are still research questions worth exploring. Consequently, it has great significance, both theoretically and practically, to explore whether TI affect HQED and compare with quantity of economic growth.

The Yangtze River Delta (YRD), covering an area of $358,000 \mathrm{~km}^{2}$, is located at the estuary of the Yangtze River [8]. It is the one of the most developed urban agglomeration, the most innovative, and the largest economic zone in China, whose GDP accounts for nearly $25 \%$ of mainland China. What's more, it is one of the only five world-class urban agglomerations in the world [9]. The HQED of YRD has played a leading and exemplary role in achieving the leap from "China speed" to "China Quality"[10]. In the process of economic development of YRD shifting from "speed" to "quality", a key question is whether the innovation-driven also shift from the innovation-led speed to innovation-led quality?

It can be found that the existing literature has the following deficiencies: First, most of the literature still focuses on the impact of TI on economic growth, social equity or environmental pollution [7, 11, 12], separately, or using a single indicator, such as total factor productivity (TFP) or green total factor productivity (GTFP), as the substitution index for HQED. It is difficult to reflect the comprehensive, dynamic and multidimensional characteristics of HQED. Second, using nations or provinces as a single decision- 
making unit is too macro to capture more micro-level information [13]. However, existing literature mainly focuses on the national or provincial level empirical analysis $[3,6,7$, 14], the city level and city group level studies are limited. Research on the comparative perspective, some research compared the impact of $R \& D$ input on regional economic growth in the Seoul and the rest of Korea [3]; some research compared the environmental regulation in facilitating the quantity and quality of green innovation [15]. Hence, there is still room for analysis from the comparative perspective of the quantity and quality of urban agglomeration growth. Thirdly, the estimation models and robustness tests of TI to economic growth under different scenarios, as well as the heterogeneity analysis under different levels of economic development need further research.

Therefore, using panel data covering 41 cities in the YRD of China, this paper conducts a comparative study to examine impacts of TI on quantity and quality of economic growth over the period 2009-2019. In detail, the contribution of the study is threefold: (1) A multidimensional comprehensive evaluation index system of HQED is established and calculated by employing the entropy weight method to characterize the quality of economic growth. (2) From a comparative perspective, this paper explores the impact of TI on quantity and quality of economic growth by different panel estimation models and robustness checks. (3) This paper investigates the innovation-economic growth link based on the panel quantile regression to perform heterogeneity analysis.

\section{HYPOTHESES AND ECONOMETRIC MODEL}

\subsection{Hypotheses}

\subsubsection{Measurement of high-quality economic development}

There have been two main approaches to the characterization of high-quality economic development (HQED): One is to measure by using single indicators such as TFP [16, 17], GTFP [7, 18, 19]. Although GTFP is modified based on the traditional TFP, considering the economic activities by incorporating environmental factors, this method still mainly focuses on the efficiency of economic development, and can't reflect the economic stability and equity. The other is to construct a multidimensional comprehensive evaluation index system, which reveal the dynamic, complex and comprehensive characteristics of HQED. Thus, establishing a multidimensional evaluation index system has become one of the most mainstream methods $[14,20-25]$. In Chinese context, the connotation of HQED is different from that of traditional quality of economic growth and more abundant. The report of the 19th Party Congress described it as higher quality, more efficient, fairer, and more sustainable development. The Development Research Center of the State Council interpreted that HQED was efficient, equitable, green, and sustainable development, aiming to meet the people's growing needs for a better life [26]. Although HQED takes into account both the ecological environment and people's livelihood while developing the economy, it is the integration of economic quantity and quality, which not only covers the quality of economic growth, but also the quantity of economic growth, because quantity is the basis of quality of economic growth [26, 27].

\subsubsection{TI and quantity of economic development}

$\mathrm{TI}$ is the core power of economic growth for countries or regions. Based on neoclassical economic growth theory, Joseph Schumpeter's innovation theory, and endogenous growth theory, many scholars have made in-depth research on TI and quantity of economic growth from different perspectives and levels. Among them, most believed that TI had a positive impact on quantity of economic growth [28, 29], while few researchers claimed that the link between the two had no direct effects. For example, MT.-C. Lin proved that technical progress did not appear to a significantly positive effect on economic growth [1].

Moreover, the basis of TI and economic conditions vary from place to place. Some scholars believed that innovation capacity differed not only among countries but also among sub-countries [7]. Many scholars have pointed out that it was more meaningful to discuss TI at a regional level [30]. Based on the above literature review, this paper proposes Hypothesis 1 .

H1: TI has a positive impact on quantity of economic growth of 41 cities in YRD.

\subsubsection{TI and high-quality economic development}

Endogenous growth theory argued that TI was the crucial driver force of economic growth. The quantity of economic growth pursued the improvement of "quantity", while HQED pursued the coexistence of "quantity" and "quality" [26, 27]. HQED can achieve sustainable economic growth by taking into account both the efficiency and equity of economic growth and integrating the concept of green development into efficiency and equity. China's economic growth urgently needs to shift from investment-driven to innovation-driven. In recent years, academia has paid more and more attention to the research of TI on the quality of economic growth.

First, TI improves the efficiency of economic development. Specifically, it is reflected in the improvement of labor productivity and capital output efficiency [6], the upgrading of industrial structure, and the improvement of resource utilization efficiency. On the one hand, it saves labor force and improves labor productivity per unit [31]; on the other hand, TI promotes the rationalization of the industrial structure, which is conducive to the upgrading of the industrial structure and the optimal allocation of resources [32].

Secondly, TI promotes the fairness of economic development. It is embodied in improving the quality of people's life such as education, medical care, pension, housing, and culture. TI not only improves the quality of the labor force and the social resources sharing, but also helps to narrow the regional gap [33].

Finally, TI enhances the sustainability of economic development $[11,12]$. It is embodied in the decline of resource energy consumption, the reduction of pollutant emission, which is conducive to green development, low-carbon development, and sustainable development $[32,33]$. Based on the above literature review, Hypothesis 2 is proposed.

$\mathrm{H} 2$ : TI has a positive impact on quality of economic growth (HQED) of 41 cities in YRD.

\subsubsection{The panel interactive fixed effect model and the quantile regression}

The panel interactive fixed effect model has drawn great attention in recent years. Compared with the classical fixed and random effects models, this method has two advantages: The slope parameters of panel interactive fixed effects model are more precise than the estimated ones of traditional panel data models [34]; The unknown factor structures simultaneously consider the fixed effects, common factors, 
and individual factor scores [35].

A large number of scholars utilized conditional mean regression to examine the impact of TI on economic growth, few studies have investigated the heterogeneous analysis for the linkage between TI and economic growth, which may result in the biased estimations. The panel quantile regression offers a strategy for examining how the driven factors affect economic growth across the entire conditional distribution of economic growth. Compared with the conditional mean regression, the quantile regression allows capturing the distributional heterogeneity of the TI-economic growth nexus and could provide more robust estimation results [36]. In addition, this method does not require the variable sequence to follow a normal distribution [12].

In short, most scholars believed that there was a positive relationship between TI and economic growth. However, a paucity of research argued that there was a nonlinear TIeconomic growth nexus or contended that TI had no significant influence on economic growth. Fruitful results have yielded on national or provincial economic growth study, but there are limited studies on the regional economic growth. To provide a greater understanding of nexus between TI and economic growth, this paper initially investigates the impact of TI on YRD's GDP per capita and HQED by mean effects, and further employs the quantile regression to test the effects on different levels of quantity and quality of economic growth.

\subsection{Econometric models}

Inspired by previous researchers [4, 6, 19], this study constructs the baseline panel estimates to test the effects of TI on the quantity and quality of economic growth, the detailed specific forms of the estimated models are as follows:

$$
\begin{gathered}
\text { perGDP }=\alpha_{0}+\alpha_{1} \mathrm{TI}_{\mathrm{it}}+\beta_{1} \mathrm{den}_{\mathrm{it}}+\beta_{2} \mathrm{fdi}_{\mathrm{it}} \\
+\beta_{3} \mathrm{is}_{\mathrm{it}}+\beta_{4} \mathrm{er}_{\mathrm{it}}+\mu_{\mathrm{i}}+v_{\mathrm{t}}+\varepsilon_{\mathrm{it}} \\
\text { HQED }=\alpha_{0}+\alpha_{1} \mathrm{TI}_{\mathrm{it}}+\beta_{1} \mathrm{den}_{\mathrm{it}}+\beta_{2} \mathrm{fdi}_{\mathrm{it}} \\
+\beta_{3} \mathrm{is}_{\mathrm{it}}+\beta_{4} \mathrm{er}_{\mathrm{it}}+\mu_{\mathrm{i}}+v_{\mathrm{t}}+\varepsilon_{\mathrm{it}}
\end{gathered}
$$

wherein, perGDP and HQED denote the dependent variables measured by GDP per capita and HQED index, respectively; the core independent variable is TI characterized by the number of granted patents sorted by the application; and den, $\mathrm{fdi}$, is, and er are the control variables, $\alpha_{0}, \alpha_{1}, \beta_{1}, \beta_{2}, \beta_{3}, \beta_{4}$ denote the parameters to be estimated, i represents different regions and $t$ denote different years, $\mu_{i}$ and $v_{t}$ are the city and time fixed effect, respectively, and $\varepsilon_{i t}$ is the random error term.

The traditional panel model merely considers the cumulative effects of city and time, which cannot reflect different sensitivity of city to the common factors by the interactive term. We further set $\varepsilon_{i t}=\lambda_{i} f_{i}+\gamma_{i t}$ to build the panel interactive fixed-effects model developed by Bai [37] in the following formula:

$$
\begin{gathered}
\text { perGDP }=\alpha_{0}+\alpha_{1} \mathrm{TI}_{\mathrm{it}}+\beta_{1} \mathrm{den}_{\mathrm{it}}+\beta_{2} \mathrm{fdi}_{\mathrm{it}} \\
+\beta_{3} \mathrm{is}_{\mathrm{it}}+\beta_{4} \mathrm{er}_{\mathrm{it}}+\mu_{\mathrm{i}}+\nu_{\mathrm{t}}+\lambda_{\mathrm{i}} \mathrm{f}_{\mathrm{t}}+\gamma_{\mathrm{it}} \\
\text { HQED }=\alpha_{0}+\alpha_{1} \mathrm{TI}_{\mathrm{it}}+\beta_{1} \mathrm{den}_{\mathrm{it}}+\beta_{2} \mathrm{fdi}_{\mathrm{it}} \\
+\beta_{3} \mathrm{is}_{\mathrm{it}}+\beta_{4} \mathrm{er}_{\mathrm{it}}+\mu_{\mathrm{i}}+\nu_{\mathrm{t}}+\lambda_{\mathrm{i}} \mathrm{f}_{\mathrm{t}}+\gamma_{\mathrm{it}}
\end{gathered}
$$

In the above formula, $\lambda_{i}$ is factor load vector, $f_{t}$ is unobservable time common factor vector, and $\gamma_{i t}$ is the random error term.

Based on (1) and (2), the panel quantile regression model is set up for the more comprehensive and robust results, it is expressed as follows $[12,36]$ :

$$
\begin{gathered}
\mathrm{Q}_{\text {perGDPit }_{\mathrm{it}}}\left(\tau \mid \mathrm{x}_{\mathrm{it}}, \lambda_{\mathrm{it}}\right)=\alpha_{\mathrm{i}}+\delta_{1} \mathrm{TI}_{\mathrm{it}}+\sigma_{1 \tau} \mathrm{den}_{\mathrm{it}}+ \\
\sigma_{2 \tau} \mathrm{fdi}_{\mathrm{it}}+\sigma_{3 \tau} \mathrm{is}_{\mathrm{it}}+\sigma_{4 \tau} \mathrm{er}_{\mathrm{it}}+\mu_{\mathrm{i}} \\
\mathrm{Q}_{\mathrm{HQED}_{\mathrm{it}}}\left(\tau \mid \mathrm{x}_{\mathrm{it}}, \lambda_{\mathrm{it}}\right)=\alpha_{\mathrm{i}}+\delta_{1} \mathrm{TI}_{\mathrm{it}}+\sigma_{1 \tau} \mathrm{den}_{\mathrm{it}}+ \\
\sigma_{2 \tau} \mathrm{fdi}_{\mathrm{it}}+\sigma_{3 \tau} \mathrm{is}_{\mathrm{it}}+\sigma_{4 \tau} \mathrm{er}_{\mathrm{it}}+\mu_{\mathrm{i}}
\end{gathered}
$$

wherein, $\tau$ represents different quantiles, $\sigma_{\tau}$ refers to the estimated coefficients of the variables at different quantiles.

\section{VARIABLE SELECTION AND DATA SOURCES}

\subsection{Variable selection}

\subsubsection{Dependent variables}

(1) Quantity of economic growth (perGDP)

In previous researches, these variables, regional GDP [7, 38], GDP per capita [38-40], labor productivity [41], GDP growth rate [38], real GDP per capita growth rate [42] have been used as the proxy variables of quantity of economic growth. However, most commonly used in the literature is GDP per capita. In line with the prior studies, this paper measures quantity of economic growth by real GDP per capita, where the GDP per capita at current prices are deflated to those at 2009 constant prices to eliminate the impact of inflation.

(2) Quality of economic growth (HQED).

Quality of economic growth is a dynamic, comprehensive, and multidimensional concept. Different from the previous studies using a single indicator, this paper constructs a HQED index by adopting a multidimensional comprehensive evaluation method to describe the quality of economic growth, which combining the economic development, social equity, and environmental protection.

Innovation development, one of the five new development concepts, is the core independent variable in our study, unlike the previous study of Du et al. [21], the index system was based on the five development concepts. On the contrary, in line with the studies of ref. [14, 20, 22], this paper focuses on the classical three pillars. The index is made up of 12 indicators from three dimensions of economic development, social equity, and green ecology, and listed in Table 1.

Among them, economic development is measured by the amount of economic growth $\left(\mathrm{B}_{1}\right)$, economic efficiency $\left(\mathrm{B}_{2}\right)$, economic stability $\left(\mathrm{B}_{3}\right)$, and industrial structure $\left(\mathrm{B}_{4}\right)$. The social equity dimension is characterized from the aspects of people's livelihood financial expenditure $\left(\mathrm{B}_{5}\right)$, income gap $\left(\mathrm{B}_{6}\right)$, medical condition $\left(\mathrm{B}_{7}\right)$, and shared cultural resources $\left(\mathrm{B}_{8}\right)$. The environmental subsystem is described by $\mathrm{PM}_{2.5}\left(\mathrm{~B}_{9}\right)$, industrial dust emission $\left(\mathrm{B}_{10}\right)$, wastewater discharge $\left(\mathrm{B}_{11}\right)$, and green coverage $\left(\mathrm{B}_{12}\right)$.

The accuracy of evaluation of regional HQED is closely related to the objectivity of the weight calculation method. Entropy weight, initially originated from a physical concept, is widely employed on indicator assessments. The advantage of the approach is that it can avoid overlapping the information [43]. The calculation progress is as follows:

Step 1: Establish the evaluation matrix of HQED. 
Table 1. The construction of index system for HQED in YRD

\begin{tabular}{cccc}
\hline Target Layer & Index Layer & Source & Contribution \\
\hline Economic & $\mathrm{B}_{1}:$ Real GDP per capita & {$[21-24]$} & Positive \\
subsystem & $\mathrm{B}_{2}:$ Labor productivity & {$[14,24,25]$} & Positive \\
$\left(\mathrm{A}_{1}\right)$ & $\mathrm{B}_{3}:$ Registered urban unemployment rate & {$[14,21,24,25]$} & Negative \\
& $\mathrm{B}_{4}:$ The ratio of tertiary and secondary industry output value & {$[21-23]$} & Positive \\
Social & $\mathrm{B}_{5}:$ Proportion of people's livelihood financial expenditure & {$[14,23]$} & Positive \\
subsystem & $\mathrm{B}_{6}:$ Urban/rural disposable income ratio & {$[21,23-25]$} & Negative \\
$\left(\mathrm{A}_{2}\right)$ & $\mathrm{B}_{7}:$ Number of beds in medical institutions per 10,000 persons & {$[21,22,24]$} & Positive \\
& $\mathrm{B}_{8}:$ Collections of public libraries per 10,000 persons & {$[21-23]$} & Positive \\
Environmental & B9:PM 2.5 & {$[26]$} & Negative \\
subsystem & B & {$[22,25]$} & Negative \\
$\left(\mathrm{A}_{3}\right)$ & $\mathrm{B}_{10}:$ Industrial Dust Emission & {$[22,24]$} & Negative \\
& $\mathrm{B}_{12}:$ Green coverage rate of built-up area & {$[22,24]$} & Positive \\
\hline
\end{tabular}

Set the original evaluation matrix of HQED in YRD:

$$
y=\left(p_{i j}\right)_{m n}, i=1,2, \ldots, m, j=1,2, \ldots, n
$$

Step 2: Normalize the original matrix of HQED, and get the standardized matrix [21]:

$$
y^{\prime}=\left(p_{i j}^{\prime}\right)_{m n}
$$

As the extremum entropy weight approach is better than other modified entropy wight methods [33]. Hence, we select the method to normalize the original matrix.

For the benefit (positive) indicator

$$
\mathrm{p}_{\mathrm{ij}}^{\prime}=\frac{\mathrm{p}_{\mathrm{ij}}-\min \left(\mathrm{p}_{\mathrm{ij}}\right)}{\max \left(\mathrm{p}_{\mathrm{ij}}\right)-\min \left(\mathrm{p}_{\mathrm{ij}}\right)}
$$

For the cost (negative) indicator:

$$
\mathrm{p}_{\mathrm{ij}}^{\prime}=\frac{\max \left(\mathrm{p}_{\mathrm{ij}}\right)-\mathrm{p}_{\mathrm{ij}}}{\max \left(\mathrm{p}_{\mathrm{ij}}\right)-\min \left(\mathrm{p}_{\mathrm{ij}}\right)}
$$

Wherein, $\max \left(p_{i j}\right)$ and $\min \left(p_{i j}\right)$ are the maximum and minimum of each indicator, respectively, $p_{i j}$ is the initial indicator, and $\mathrm{p}_{\mathrm{ij}}^{\prime}$ is the standardized indicator.

Step 3: Calculate and obtain the information entropy and the weight of each index.

The information entropy of each indicator:

$$
\mathrm{e}_{\mathrm{i}}=-\frac{1}{\ln \mathrm{n}} \sum_{\mathrm{j}=1}^{\mathrm{n}} \mathrm{p}_{\mathrm{ij}}^{\prime} \ln \mathrm{p}_{\mathrm{ij}}^{\prime}
$$

The weight of each indicator

$$
\omega_{i}=\frac{1-e_{i}}{m-\sum_{i=1}^{m} e_{i}}
$$

Step 4: Synthesize an index to express the HQED of each city in YRD.

Construct the weighted standardized evaluation matrix:

$$
\mathrm{V}=\mathrm{v}_{\mathrm{ij}}=\omega_{\mathrm{i}}\left(\mathrm{p}_{\mathrm{ij}}^{\prime}\right)_{\mathrm{mn}}
$$

\subsubsection{Core independent variable}

Some scholars proved that innovation output variables more directly and effectively identify than innovation input ones to reflect regional innovation capacity $[6,13]$. The indicators commonly used to characterize the capacity of regional innovation output are numbers of patent applications and numbers of patent grants [13]. Therefore, in line with the prior studies, this study uses three kinds of patent application quantity per 10,000 persons to act as the proxy for TI, capturing the information on the TI-economic growth link.

\subsubsection{Control variables}

In a certain region, other factors may affect economic growth besides TI. To reduce errors in evaluating the effects, four control variables are introduced into the model [8]. Industrial structure (is) [6] is represented by the ratio of tertiary industry output value to secondary industry output value. Openness degree (fdi) is denoted by the ratio of foreign direct investment to GDP [4]. Environmental regulation (er) is characterized by the utilization rate of industrial solid waste. Population size is (den) defined by the regional population density.

\subsection{Data sources}

Due to the representativeness and availability of data, we choose panel data of 41 cities in YRD over the period of 20092019. The raw data is devised from the China Urban Statistical Yearbook (2010-2020), China Science and Technology Statistical Yearbook (2010-2020), Shanghai Statistical Yearbook (2010-2020), Jiangsu Statistical Yearbook (2010-2020), Zhejiang Statistical Yearbook (20102020), Anhui Statistical Yearbook (2010-2020), the website of Statistical Bulletin (2010-2020) of each province/city, and the Wind Economic Database. A small fraction of missing data is estimated by the interpolation or average growth rate.

To eliminate heteroscedasticity and avoid the estimation error caused by different dimensions, all control variables were logarithmically processed. It is worth emphasizing that the minimum and maximum of TI and perGDP are 0 and 1 , respectively. Given the variable of HQED normalized in the process of index calculation, inspired by the prior study [36], this study has normalized the original value of TI and perGDP by using same normalization method as HQED to unify the criteria of core variables (perGDP and TI) for comparative analysis. Table 2 demonstrates descriptive statistical results. 
Table 2. Descriptive statistics for the variables

\begin{tabular}{cccccc}
\hline Variables & $\mathbf{N}$ & Mean & Sd & Min & Max \\
\hline HQED & 451 & 0.385 & 0.118 & 0.187 & 0.784 \\
perGDP & 451 & 0.329 & 0.216 & 0.000 & 1.000 \\
TI & 451 & 0.182 & 0.177 & 0.000 & 1.000 \\
Inden & 451 & 6.374 & 0.562 & 4.979 & 8.251 \\
Infdi & 451 & 11.284 & 1.298 & 7.977 & 14.900 \\
Inis & 451 & 4.512 & 0.338 & 3.443 & 5.595 \\
Iner & 451 & 4.522 & 0.106 & 3.691 & 4.607 \\
\hline
\end{tabular}

The empirical analysis of this paper focuses on the period of 2009-2019. There are two reasons justifying our attention to this period. One is due to the influence of the global economic crisis in 2009, the quality of economic growth is of greater concern to the government, and innovation-driven the high-quality development of the economy rose to a higher strategic position. The other is that, the Chinese government has paid more attention to the integration of the YRD starting from 2009, and launched a series of policies, guiding plans, which were of strategic significance for innovation and economic development in the YRD region [8].

\section{EMPIRICAL ANALYSIS}

\subsection{Measurement of HQED index}

Based on the assessment index system and measurement model of regional HQED, Table 3 shows the weight of each indicator of 41 cities in YRD during 2009-2019 and Table 4 gives information that the results of HQED index. Although the HQED index of some cities had slight fluctuations in individual years, the whole tendency from 2009 to 2019 generally saw an upward trend. Among the city group, the top five cities with the highest HQED values are Shanghai, Hangzhou, Nanjing, Suzhou and Wuxi; In contrast, the bottom five ones are Bozhou, Xuancheng, Suzhou, Anqing and Huainan. The difference between the maximum and the minimum is approximately 0.6 , indicating the performance of HQED in YRD is unbalanced. Specifically, in 2019, Shanghai Municipality has the highest level of HQED, and the value is close to 0.8 , which plays a leading role in the group. In contrast, Huainan is at the bottom with the figure of 0.198 . Among the region group, the mean value order of HQED level from high to low is Shanghai Municipality, Jiangsu Province, Zhejiang Province, and Anhui Province. The findings indicate that the HQED level of the Anhui province is in a backward position compared with the Shanghai, Jiangsu and Zhejiang, demonstrating that there is still great development potential and growth space.

\subsection{Unit root test of panel data}

Because the modeling steps of stationary data and nonstationary data are quite different, it is necessary to test the panel unit root of variable sequences to address the spurious regression phenomenon prior to performing panel regression analysis. We apply three testing procedures to determine the stability of variables: LLC test, IPS test, and ADF test. Table 5 depicts the results of panel unit root test. The null hypothesis for LLC test, IPS test, and ADF-Fisher test imply nonstationarity. Meanwhile, the alternative hypothesis assumes that the considered variable is stationary. The variables, perGDP, Inden, Infdi, lnis, and lner, all passed the three tests at the $1 \%$ significance level; Both HQED and TI variables passed LLC test and ADF-Fisher test at 1\% significance level, while passed the IPS test at the 5\% significance level. Hence, it can be concluded that the variables are stationary and it is possible to estimate the panel data models.

\subsection{Different scenarios of panel regression}

\subsubsection{Panel regression}

Before the regression, we examined the variance expansion coefficients of independent variables, showing that the variance expansion coefficients are all less than 3, which indicates that there is no significant multicollinearity.

This study has conducted the estimations and shown in Table 6. All explanatory variables are statistically significant under varying robust error estimations models. Obviously, no matter with any estimated models, the coefficients of TI are significantly positive, implying strongly that TI affects both quantity and quality of economic growth in a significant and positive way. Hypothesis 1 and 2 are supported.

Specifically, Table 6 presents the results of Pooled-OLS, fixed-effects, random-effects, double fixed-effects, and interactive fixed-effects model, in columns (1)-(5), respectively. It is found that all the coefficients of TI to the quantity of economic growth are larger than that of the quality, indicating that TI promotes quantity of economic growth more than that of quality. For instance, as shown in column (1), the coefficients of the TI are 0.884 on perGDP and 0.295 on HQED, which are both significant at 1\%-level.

In particular, Model 5 sets up a panel interaction fixedeffects model by introducing the interaction terms of the city and year fixation based on Eq. (3) and Eq. (4). Column (5) reports that the coefficients of TI are 0.191 (significant at 1\%level) on perGDP and 0.060 (significant at 5\%-level) on HQED.

Table 3. The weights of the indicators of 41cities in YRD, China (2009-2019)

\begin{tabular}{|c|c|c|c|c|c|c|c|c|c|c|c|c|}
\hline Indicator & $\mathbf{B}_{1}$ & $\mathbf{B}_{2}$ & $\mathbf{B}_{3}$ & $\mathbf{B}_{4}$ & B5 $_{5}$ & B6 & $\mathbf{B}_{7}$ & B8 & B9 & $\mathbf{B}_{10}$ & $\mathbf{B}_{11}$ & $\mathbf{B}_{12}$ \\
\hline 2009 & 0.1181 & 0.1159 & 0.0841 & 0.0829 & 0.1042 & 0.0305 & 0.0953 & 0.2493 & 0.0305 & 0.0433 & 0.0192 & 0.0265 \\
\hline 2010 & 0.1219 & 0.1162 & 0.0927 & 0.0627 & 0.0467 & 0.0471 & 0.1074 & 0.2697 & 0.0455 & 0.0456 & 0.0212 & 0.0232 \\
\hline 2011 & 0.1185 & 0.1135 & 0.1005 & 0.0644 & 0.0809 & 0.0373 & 0.1135 & 0.2590 & 0.0347 & 0.0353 & 0.0203 & 0.0220 \\
\hline 2012 & 0.1205 & 0.1088 & 0.0878 & 0.0741 & 0.0651 & 0.0553 & 0.2411 & 0.1002 & 0.0487 & 0.0232 & 0.0205 & 0.0546 \\
\hline 2013 & 0.1165 & 0.1037 & 0.0799 & 0.0773 & 0.0499 & 0.0468 & 0.1112 & 0.2239 & 0.0475 & 0.0464 & 0.0207 & 0.0761 \\
\hline 2014 & 0.1177 & 0.1059 & 0.0915 & 0.0739 & 0.0339 & 0.0561 & 0.1223 & 0.2412 & 0.0577 & 0.0419 & 0.0206 & 0.0371 \\
\hline 2015 & 0.1218 & 0.1108 & 0.0826 & 0.0916 & 0.0385 & 0.0331 & 0.1539 & 0.2367 & 0.0331 & 0.0411 & 0.0219 & 0.0350 \\
\hline 2016 & 0.1173 & 0.1153 & 0.0716 & 0.1018 & 0.0347 & 0.0421 & 0.1033 & 0.2239 & 0.0423 & 0.0597 & 0.0248 & 0.0631 \\
\hline 2017 & 0.1266 & 0.1231 & 0.0493 & 0.0968 & 0.0296 & 0.0616 & 0.1162 & 0.2303 & 0.0619 & 0.0371 & 0.0274 & 0.0401 \\
\hline 2018 & 0.1213 & 0.1190 & 0.0550 & 0.1174 & 0.0273 & 0.0578 & 0.1108 & 0.2307 & 0.0578 & 0.0268 & 0.0275 & 0.0486 \\
\hline 2019 & 0.1357 & 0.1196 & 0.0359 & 0.1343 & 0.0463 & 0.0514 & 0.0917 & 0.2492 & 0.0513 & 0.0175 & 0.0195 & 0.0477 \\
\hline
\end{tabular}


Table 4. Measurement Results of HQED Index of 41 cities in YRD, China (2009-2019)

\begin{tabular}{|c|c|c|c|c|c|c|c|c|c|c|c|c|}
\hline Region & City & 2009 & 2010 & 2011 & 2012 & 2013 & 2014 & 2015 & 2016 & 2017 & 2018 & 2019 \\
\hline \multirow[t]{6}{*}{ Shanghai Municipality } & Shanghai & 0.691 & 0.723 & 0.706 & 0.682 & 0.707 & 0.694 & 0.732 & 0.688 & 0.729 & 0.681 & 0.784 \\
\hline & Nanjing & 0.510 & 0.548 & 0.547 & 0.570 & 0.491 & 0.580 & 0.670 & 0.604 & 0.625 & 0.634 & 0.600 \\
\hline & Wuxi & 0.460 & 0.515 & 0.537 & 0.562 & 0.457 & 0.562 & 0.545 & 0.565 & 0.584 & 0.591 & 0.520 \\
\hline & Xuzhou & 0.321 & 0.302 & 0.332 & 0.287 & 0.226 & 0.321 & 0.339 & 0.388 & 0.365 & 0.366 & 0.355 \\
\hline & Changzhou & 0.417 & 0.467 & 0.478 & 0.522 & 0.433 & 0.544 & 0.537 & 0.528 & 0.544 & 0.533 & 0.505 \\
\hline & SUzhou & 0.500 & 0.535 & 0.550 & 0.597 & 0.499 & 0.613 & 0.580 & 0.612 & 0.614 & 0.597 & 0.550 \\
\hline \multirow{13}{*}{$\begin{array}{l}\text { Jiangsu } \\
\text { Province }\end{array}$} & Nantong & 0.375 & 0.405 & 0.427 & 0.438 & 0.349 & 0.450 & 0.421 & 0.469 & 0.446 & 0.453 & 0.436 \\
\hline & Lianyungang & 0.323 & 0.346 & 0.321 & 0.341 & 0.276 & 0.344 & 0.338 & 0.374 & 0.343 & 0.353 & 0.331 \\
\hline & Huaian & 0.274 & 0.304 & 0.329 & 0.355 & 0.301 & 0.394 & 0.374 & 0.412 & 0.369 & 0.365 & 0.348 \\
\hline & Yancheng & 0.311 & 0.358 & 0.350 & 0.331 & 0.281 & 0.388 & 0.341 & 0.402 & 0.384 & 0.382 & 0.370 \\
\hline & Yangzhou & 0.349 & 0.425 & 0.404 & 0.414 & 0.361 & 0.462 & 0.449 & 0.497 & 0.484 & 0.484 & 0.458 \\
\hline & Zhenjiang & 0.416 & 0.473 & 0.455 & 0.483 & 0.417 & 0.523 & 0.495 & 0.536 & 0.496 & 0.480 & 0.450 \\
\hline & TAizhou & 0.324 & 0.383 & 0.371 & 0.396 & 0.344 & 0.448 & 0.414 & 0.472 & 0.457 & 0.457 & 0.410 \\
\hline & Suqian & 0.272 & 0.317 & 0.308 & 0.318 & 0.273 & 0.335 & 0.287 & 0.350 & 0.364 & 0.348 & 0.308 \\
\hline & Mean & 0.373 & 0.414 & 0.416 & 0.432 & 0.362 & 0.459 & 0.445 & 0.478 & 0.467 & 0.465 & 0.434 \\
\hline & Hangzhou & 0.535 & 0.610 & 0.632 & 0.662 & 0.550 & 0.656 & 0.705 & 0.656 & 0.654 & 0.648 & 0.616 \\
\hline & Ningbo & 0.442 & 0.457 & 0.470 & 0.487 & 0.415 & 0.501 & 0.506 & 0.451 & 0.414 & 0.414 & 0.420 \\
\hline & Wenzhou & 0.338 & 0.376 & 0.364 & 0.396 & 0.345 & 0.452 & 0.391 & 0.411 & 0.428 & 0.415 & 0.386 \\
\hline & Jiaxing & 0.383 & 0.450 & 0.430 & 0.477 & 0.455 & 0.513 & 0.472 & 0.509 & 0.464 & 0.408 & 0.423 \\
\hline \multirow{15}{*}{$\begin{array}{l}\text { Zhejiang } \\
\text { Province }\end{array}$} & Huzhou & 0.354 & 0.423 & 0.392 & 0.387 & 0.350 & 0.453 & 0.400 & 0.446 & 0.420 & 0.408 & 0.377 \\
\hline & Shaoxing & 0.388 & 0.456 & 0.442 & 0.460 & 0.385 & 0.465 & 0.440 & 0.490 & 0.445 & 0.430 & 0.420 \\
\hline & Jinhua & 0.351 & 0.394 & 0.369 & 0.379 & 0.333 & 0.406 & 0.367 & 0.425 & 0.438 & 0.440 & 0.385 \\
\hline & Quzhou & 0.290 & 0.338 & 0.313 & 0.305 & 0.260 & 0.307 & 0.305 & 0.389 & 0.398 & 0.424 & 0.358 \\
\hline & Zhoushan & 0.422 & 0.508 & 0.492 & 0.507 & 0.465 & 0.559 & 0.549 & 0.540 & 0.550 & 0.548 & 0.509 \\
\hline & Taizhou & 0.333 & 0.365 & 0.352 & 0.350 & 0.318 & 0.415 & 0.371 & 0.451 & 0.467 & 0.445 & 0.351 \\
\hline & Lishui & 0.304 & 0.348 & 0.321 & 0.343 & 0.323 & 0.415 & 0.368 & 0.487 & 0.469 & 0.491 & 0.389 \\
\hline & Mean & 0.376 & 0.430 & 0.416 & 0.432 & 0.382 & 0.467 & 0.443 & 0.478 & 0.468 & 0.461 & 0.421 \\
\hline & Hefei & 0.398 & 0.402 & 0.313 & 0.325 & 0.310 & 0.369 & 0.380 & 0.363 & 0.405 & 0.413 & 0.430 \\
\hline & Wuhu & 0.372 & 0.426 & 0.248 & 0.248 & 0.225 & 0.300 & 0.318 & 0.327 & 0.348 & 0.346 & 0.408 \\
\hline & Bengbu & 0.250 & 0.289 & 0.304 & 0.326 & 0.299 & 0.345 & 0.297 & 0.331 & 0.354 & 0.334 & 0.315 \\
\hline & Huainan & 0.261 & 0.187 & 0.214 & 0.205 & 0.191 & 0.223 & 0.225 & 0.200 & 0.202 & 0.196 & 0.212 \\
\hline & Maanshan & 0.386 & 0.413 & 0.347 & 0.338 & 0.255 & 0.285 & 0.288 & 0.282 & 0.281 & 0.298 & 0.389 \\
\hline & & 0.253 & 0.279 & 0.291 & 0.279 & 0.290 & 0.325 & 0.279 & 0.286 & 0.327 & 0.311 & 0.304 \\
\hline & Tons & & & & & & & & 0.355 & 0.321 & 0.317 & 0.347 \\
\hline \multirow{10}{*}{$\begin{array}{c}\text { Anhui } \\
\text { Province }\end{array}$} & Anqing & 0.253 & 0.241 & 0.228 & 0.237 & 0.246 & 0.250 & 0.245 & 0.271 & 0.282 & 0.260 & 0.269 \\
\hline & Huangshan & 0.366 & 0.361 & 0.353 & 0.356 & 0.390 & 0.386 & 0.340 & 0.391 & 0.411 & 0.442 & 0.384 \\
\hline & Chuzhou & 0.239 & 0.286 & 0.289 & 0.260 & 0.222 & 0.264 & 0.218 & 0.261 & 0.294 & 0.276 & 0.271 \\
\hline & Fuyang & 0.285 & 0.258 & 0.274 & 0.276 & 0.229 & 0.317 & 0.245 & 0.258 & 0.287 & 0.279 & 0.252 \\
\hline & Suzhou & 0.219 & 0.231 & 0.205 & 0.240 & 0.208 & 0.254 & 0.254 & 0.275 & 0.269 & 0.262 & 0.231 \\
\hline & Liuan & 0.233 & 0.261 & 0.224 & 0.244 & 0.234 & 0.227 & 0.200 & 0.227 & 0.268 & 0.259 & 0.254 \\
\hline & Bozhou & 0.248 & 0.291 & 0.278 & 0.277 & 0.256 & 0.269 & 0.217 & 0.268 & 0.264 & 0.245 & 0.259 \\
\hline & Chizhou & 0.247 & 0.280 & 0.289 & 0.283 & 0.272 & 0.309 & 0.303 & 0.329 & 0.337 & 0.338 & 0.290 \\
\hline & Xuancheng & 0.292 & 0.316 & 0.269 & 0.261 & 0.291 & 0.302 & 0.257 & 0.291 & 0.322 & 0.297 & 0.301 \\
\hline & Mean & 0.294 & 0.310 & 0.285 & 0.288 & 0.270 & 0.306 & 0.274 & 0.295 & 0.311 & 0.304 & 0.307 \\
\hline
\end{tabular}

Table 5. Panel unit root test results

\begin{tabular}{cccc}
\hline Variables & LLC Test & IPS Test & ADF Test \\
\hline perGDP & $-4.6355^{* * *}$ & $-2.6441^{* * *}$ & $248.6614^{* * *}$ \\
HQED & $-5.5764 * * *$ & $-1.8704^{* *}$ & $125.8196^{* * *}$ \\
TI & $-3.4094 * * *$ & $-1.6670^{* *}$ & $137.2657 * * *$ \\
lnden & $-29.7655^{* * *}$ & $-10.7079 * * *$ & $290.6962 * * *$ \\
lnfdi & $-34.4782 * * *$ & $-18.3184 * * *$ & $829.6154 * * *$ \\
lnis & $-13.4866 * * *$ & $-4.4321 * * *$ & $200.5129 * * *$ \\
lner & $-5.5040^{* * *}$ & $-3.2090^{* * *}$ & $197.3033^{* * *}$ \\
\hline
\end{tabular}

In order to weaken the influence of heteroscedasticity, intragroup autocorrelation, and cross-section autocorrelation on the estimation results [44], we use PCSE command estimators. Owing to space constraints, we merely show the results, which the coefficients of TI are 0.384 on perGDP and 0.087 on HQED, consistent with the above results.

By means of Hausman test both for perGDP and HQED at the level of $1 \%$ significance, suggesting the fixed-effects model is superior to the random-effects model. Thus, in this paper, double fixed-effects model is used to explain the results. In terms of core explanatory variable, the TI increases by one unit, the perGDP index grows by 0.396 unit, and the HQED index rises by 0.095 unit. The impact of TI on quantity of economic growth is almost four times higher than that of quality.

In terms of control variables, the industrial structure has a statistically positive impact on quality of economic growth, thereby promoting the upgrading of industrial structure, and significantly affecting regional HQED. On the contrary, the openness degree negatively influences both quantity and quality of economic growth, which indicates that the rapid accumulation of foreign investment does not promote the development of the regional economy, but instead support the theory of pollution paradise to a certain extent. The regions may attract foreign investment at the expense of environmental pollution. What's more, the environmental regulation and population size have no significant effect on quality of economic growth.

\subsubsection{Robustness check}

To test the results are stable, we apply five alternative estimations as our robustness checks. We all adopt double 
fixed-effects model, and the results are listed in Table 7.

(1) Replacing the independent variable.

Inspired by ref. [4, 6, 13], this paper selects three kinds of patent licensing quantity per 10,000 persons to replace TI, denoted as TI2. Table 7 demonstrates the estimation results when TI 2 is used as a proxy indicator for TI in Column 1 and 2 . The results confirm that the regression coefficients of the new variables remain unchanged, indicating that regional TI not only promotes the quantity of economic growth but also that of the quality.

(2) Replacing the dependent variables.

In addition to replacing the measurement of the explanatory variable, it is necessary to substitute the key dependent variables. We replace per capita GDP as labor productivity to measure the quantity of economic growth, denoted as LA, and the dependent variable of HQED index is recalculated by principal component analysis, represented as PHQED. The regression results are shown in Table 7 of column 3 and 4 . The direction of coefficients for the key explanatory variables and overall significance are consistent with the above results. which provides evidence to support the non-fortuity of the estimation results.

(3) Adapting different regression models.

This study constructs five different econometric models, namely, Pooled-OLS, fixed-effects model, random-effects model, double fixed-effects model, and interactive fixedeffects model for the panel data. A significantly positive linear relationship between TI and economic growth is still evident in terms of both quantity and quality. The results are consistent with those shown in above Table 6 , and confirms the validity of the baseline results.

Table 6. Empirical results of TI affecting the quantity/quality of economic growth in YRD

\begin{tabular}{|c|c|c|c|c|c|c|c|c|c|c|}
\hline \multirow{2}{*}{ Models } & \multicolumn{2}{|c|}{ (1) OLS } & \multicolumn{2}{|c|}{ (2) $\mathrm{FE}$} & \multicolumn{2}{|c|}{ (3) $\mathrm{RE}$} & \multicolumn{2}{|c|}{ (4) Double-FE } & \multicolumn{2}{|c|}{ (5) INFE } \\
\hline & perGDP & HQED & perGDP & HQED & perGDP & HQED & perGDP & HQED & perGDP & HQED \\
\hline \multirow[t]{2}{*}{ TI } & $0.884 * * *$ & $0.295 * * *$ & $0.678 * * *$ & $0.092 * *$ & $0.757 * * *$ & $0.136 * * *$ & $0.396^{* * *}$ & $0.095 * *$ & $0.191 * * *$ & $0.060 * *$ \\
\hline & 08) & $(0.054)$ & $(0.096)$ & $(0$. & $(0.084)$ & $(0.034)$ & (0.089) & $(0.037)$ & $(0.027)$ & $(0.025)$ \\
\hline \multirow[t]{2}{*}{ lnden } & 0.026 & 0.030 & 0.237 & 0.133 & $0.067 * *$ & $0.077 * *$ & 0.116 & 0.119 & $0.106 * * *$ & $0.084 * *$ \\
\hline & $(0.023)$ & $(0.021)$ & $(0.177)$ & $(0.075)$ & $(0.030)$ & $(0.026)$ & $(0.130)$ & $(0.080)$ & $(0.032)$ & $(0.033)$ \\
\hline \multirow[t]{2}{*}{$\operatorname{lnfdi}$} & 0.020 & 0.016 & 0.006 & -0.004 & 0.008 & -0.001 & $-0.017 * *$ & $-0.006 * *$ & -0.004 & -0.001 \\
\hline & (0.013) & $(0.010)$ & $(0.006)$ & $(0.003)$ & $(0.006)$ & $(0.004)$ & $(0.006)$ & $(0.003)$ & $(0.003)$ & $(0.003)$ \\
\hline \multirow[t]{2}{*}{$\operatorname{lnis}$} & $0.100^{* *}$ & $0.117 * *$ & $0.211 * * *$ & 0.05 & $0.177 * * *$ & $0.058 * *$ & 0.019 & $0.051 * *$ & 0.000 & $0.049 * * *$ \\
\hline & & $(0.034)$ & & & & & $(0.0$ & & $(0.016)$ & $(0.015)$ \\
\hline \multirow[t]{2}{*}{ lner } & -0.020 & 0. & $-0.071 * *$ & -0 . & -0.0 & -0. & $-0.070 * *$ & -0.016 & 0.001 & 0.015 \\
\hline & & & & & & & & & & $(0.017)$ \\
\hline \multirow[t]{2}{*}{ Constant } & -0.579 & -0.642 & -2.008 & -0.570 & $-0.839 * *$ & -0.280 & 0.069 & -0.432 & -0.337 & -0.444 \\
\hline & $(0.503)$ & $(0.3$ & & & & $(0.2$ & $(0.9$ & 27) & $(0.232)$ & $(0.239)$ \\
\hline $\mathrm{N}$ & 451 & 451 & 451 & 451 & 451 & 451 & 451 & 451 & 451 & 451 \\
\hline $\mathrm{R}^{2}$ & 0.784 & 0.650 & 0.663 & 0.220 & 0.655 & 0.208 & 0.834 & 0.443 & & \\
\hline
\end{tabular}

Note: Robust standard errors are in all parentheses. *,**,*** denote significant at the levels of $10 \%, 5 \%$, and $1 \%$, respectively. The same as below tables.

Table 7. Results of robustness test

\begin{tabular}{|c|c|c|c|c|c|c|c|c|}
\hline Nexus & $\begin{array}{c}\text { (1) } \\
\text { TI2-perGDP }\end{array}$ & $\begin{array}{c}\text { (2) } \\
\text { TI2-HQED }\end{array}$ & $\begin{array}{c}\text { (3) } \\
\text { TI-LA }\end{array}$ & $\begin{array}{c}(4) \\
\text { TI-PHQED }\end{array}$ & $\begin{array}{c}\text { (5) } \\
\text { TI-perGDP }\end{array}$ & $\begin{array}{c}\text { (6) } \\
\text { TI-HQED }\end{array}$ & $\begin{array}{c}(7) \\
\text { TI-perGDP }\end{array}$ & $\begin{array}{c}\text { (8) } \\
\text { TI-HQED }\end{array}$ \\
\hline TI or & $0.373 * *$ & $0.130 * *$ & $0.352 * *$ & $0.128 * *$ & $0.366 * * *$ & $0.098 * *$ & $0.327 * * *$ & $0.084 * *$ \\
\hline TI2 & $(0.132)$ & $(0.042)$ & $(0.099)$ & $(0.041)$ & $(0.090)$ & $(0.038)$ & (0.077) & $(0.040)$ \\
\hline lnden & 0.135 & 0.115 & 0.128 & 0.145 & 0.100 & 0.120 & 0.092 & 0.122 \\
\hline & $(0.138)$ & $(0.083)$ & $(0.136)$ & $(0.089)$ & $(0.127)$ & (0.079) & $(0.138)$ & $(0.087)$ \\
\hline $\operatorname{lnfdi}$ & $\begin{array}{c}-0.016 * * \\
(0.007)\end{array}$ & $\begin{array}{l}-0.005 \\
(0.003)\end{array}$ & $\begin{array}{c}-0.020 * * \\
(0.008)\end{array}$ & $\begin{array}{l}-0.006 \\
(0.003)\end{array}$ & $\begin{array}{c}-0.014 * * \\
(0.006)\end{array}$ & $\begin{array}{c}-0.006 * * \\
(0.003)\end{array}$ & $\begin{array}{c}-0.017 * * \\
(0.007)\end{array}$ & $\begin{array}{c}-0.006 * * \\
(0.003)\end{array}$ \\
\hline $\operatorname{lnis}$ & $\begin{array}{l}-0.022 \\
(0.049)\end{array}$ & $\begin{array}{c}0.039 \\
(0.023)\end{array}$ & $\begin{array}{l}-0.061 \\
(0.048)\end{array}$ & $\begin{array}{c}0.017 \\
(0.028)\end{array}$ & $\begin{array}{l}-0.044 \\
(0.049)\end{array}$ & $\begin{array}{c}0.036 \\
(0.023)\end{array}$ & $\begin{array}{l}-0.059 \\
(0.049)\end{array}$ & $\begin{array}{c}0.035 \\
(0.024)\end{array}$ \\
\hline lner & $\begin{array}{c}-0.077 * * \\
(0.028)\end{array}$ & $\begin{array}{l}-0.017 \\
(0.022)\end{array}$ & $\begin{array}{c}-0.091 * * \\
(0.029)\end{array}$ & $\begin{array}{l}-0.013 \\
(0.025)\end{array}$ & $\begin{array}{c}-0.069 * * \\
(0.025)\end{array}$ & $\begin{array}{c}-0.016 \\
(0.022)\end{array}$ & $\begin{array}{c}-0.055^{* *} \\
(0.025)\end{array}$ & $\begin{array}{l}-0.017 \\
(0.022)\end{array}$ \\
\hline lnInter & & & & & $\begin{array}{l}-0.044 \\
(0.023)\end{array}$ & $\begin{array}{c}0.005 \\
(0.009)\end{array}$ & & \\
\hline Constant & $\begin{array}{l}-0.090 \\
(0.972)\end{array}$ & $\begin{array}{l}-0.422 \\
(0.546)\end{array}$ & $\begin{array}{c}0.216 \\
(0.960)\end{array}$ & $\begin{array}{l}-0.535 \\
(0.596)\end{array}$ & $\begin{array}{c}0.326 \\
(0.939)\end{array}$ & $\begin{array}{l}-0.459 \\
(0.520)\end{array}$ & $\begin{array}{c}0.235 \\
(0.991)\end{array}$ & $\begin{array}{l}-0.461 \\
(0.575)\end{array}$ \\
\hline Observations & 451 & 451 & 451 & 451 & 451 & 451 & 407 & 407 \\
\hline $\mathrm{R}^{2}$ & 0.821 & 0.454 & 0.800 & 0.412 & 0.839 & 0.443 & 0.816 & 0.449 \\
\hline
\end{tabular}

Table 8. Quantile regression results of TI affects the quantity and quality of economic growth

\begin{tabular}{cccccccccc}
\hline Quantile & $\mathbf{0 . 1 0}$ & $\mathbf{0 . 2 0}$ & $\mathbf{0 . 3 0}$ & $\mathbf{0 . 4 0}$ & $\mathbf{0 . 5 0}$ & $\mathbf{0 . 6 0}$ & $\mathbf{0 . 7 0}$ & $\mathbf{0 . 8 0}$ & $\mathbf{0 . 9 0}$ \\
\hline TI to perGDP & $0.486^{* * *}$ & $0.556^{* * *}$ & $0.598^{* * *}$ & $0.630^{* * *}$ & $0.667^{* * *}$ & $0.715^{* * *}$ & $0.759^{* * *}$ & $0.804^{* * *}$ & $0.867^{* * *}$ \\
& $(0.132)$ & $(0.100)$ & $(0.084)$ & $(0.074)$ & $(0.068)$ & $(0.067)$ & $(0.074)$ & $(0.088)$ & $(0.114)$ \\
TI to HQED & 0.061 & 0.072 & $0.080^{* *}$ & $0.088^{* * *}$ & $0.094 * * *$ & $0.100^{* * *}$ & $0.107^{* * *}$ & $0.114^{* * *}$ & $0.122^{* *}$ \\
& $(0.050)$ & $(0.038)$ & $(0.031)$ & $(0.026)$ & $(0.025)$ & $(0.026)$ & $(0.029)$ & $(0.034)$ & $(0.042)$ \\
Control variables & YES & YES & YES & YES & YES & YES & YES & YES & YES \\
Observations & 451 & 451 & 451 & 451 & 451 & 451 & 451 & 451 & 451 \\
\hline
\end{tabular}


(4) Adding control variables.

Considering the possible influence of the control variables on the results, we add another new control variable, the number of regional Internet broadband subscribers to express the digital information level, denoted as InInter. The results are listed in column 5 and 6 of Table 7, supporting the above findings.

(5) Removing the municipality and provincial capitals

In view of the special administrative status incomparable with ordinary prefecture-level cities, we exclude Shanghai Municipality and the three provincial capitals, namely, Nanjing, Hangzhou and Hefei, and analyze the remaining 407 samples again [45]. The results, showing in column 7 and 8 of Table 7, also verify the hypothesis.

To summarize, the robustness test from the perspective of variables, measurement methods and sample data all proves that the empirical results are consistent. Thus, we conclude that the parameters of the above models are evidently stable.

\subsection{Panel quantile regression}

Despite the advantages as listed, all the estimators above are based on mean effects, which may have partial absence and cannot describe the heterogeneous effects on economic growth across the entire distribution. Hence, this paper further employs quantile regression to provide a more detailed and reliable view of TI on economic growth in 41 cities of YRD. We capture the varying effects on quantity and quality of economic growth by estimating the models of quantiles $\tau=0.10$, $0.20,0.3, \ldots, 0.9$. The results are shown in Table 8 .

Specifically, the outcomes from panel quantile estimation with double fixed effects indicate that the impact of TI to quality of economic growth is insignificant at the 10th and 20th quantiles, but they are positive and significant at the remaining quantiles of both quantity and quality of economic growth. Moreover, the regression coefficient increases gradually with the shift from low quantile to high quantile. In other words, in higher GDP per capita or HQED levels of cities, TI contributes more to economic growth. This may be because, in higher GDP per capita or HQED levels of cities, the advancement of TI makes the productions more efficiently than in lower ones. It also can be explained by the theory of Innovation Paradox [7]. The innovation return of the regions with relatively high economic growth level is higher than those with relatively low economic growth level. These findings further support hypotheses 1 and 2 .

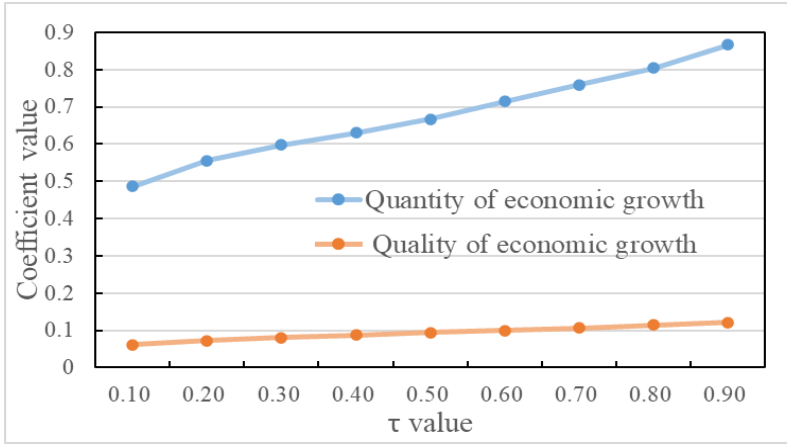

Figure 1. The TI coefficient contrast chart across percentiles

By contrast, and more interesting, at the same point of the quantiles, quantity of economic growth entirely has a larger coefficient than the quality of economic growth. Additionally, this gap widens as we move to the higher percentile, as illustrated in Figure 1. These findings show that the influence of innovation-driven for the quality of economic growth is weaker than the quantity of economic growth. Thus, governments should pay more attention to improve the situation by increasing investment in innovation inputs, constructing a more dynamic and competitive innovative environment, promoting the positive role of innovation in driving the HQED.

\section{CONCLUSIONS}

This paper contributes to the literature by conducting a comparative study to examine impacts of TI on quantity and quality of economic growth by using the panel data covering 41 cities in the YRD of China over the period 2009-2019. The main findings can be summarized as follows:

(1) The cities in YRD have achieved extensive quantity and quality of economic development in general. Although most cities in YRD have experienced HQED growth during the sample period, the greater the cities with the economic development, the greater cities with the increment in HQED, indicating that the gap in HQED among regions is widening.

(2) TI plays a significant role in promoting both the quantity and the quality of regional economic growth. Under different scenarios of the panel data estimation models, the same conclusion is drawn that the regression coefficient of TI to the quantity of economic growth is larger than that to the quality of economic growth, which shows that TI has a stronger impact on quantity of economic growth.

(3) The higher the level of economic growth, the stronger the driving effect of TI. The effect on quantity of economic growth is also stronger than that of quality under the conditional distribution, which indicates the innovation return of regions with relatively high economic growth levels is higher than that of regions with relatively low economic growth levels.

Based on the above findings, the following policy recommendations were proposed:

(1) Aiming for the economic high-quality development, policymakers should vigorously develop innovation activities. First, the governments should increase the input of technology innovation, such as the input intensity of $R \& D$ funds, the ratio of basic research funds in total R\&D funds. Secondly, give full play to the role of the government in supporting the policy environment for innovation-driven development, incentive function of achievement transformation. Thirdly, they should encourage the knowledge spillover, technology spillover and spatial spillover effects of innovation diffusion to accelerate the transformation and application of innovation output, promoting a benign synergy mechanism between TI and HQED to form.

(2) Innovation investments should target regions where the quality of economic growth is relatively low, we should not only explicit factors such as the introduction of capital and talents, but also enhance the local complementarities through implicit factors such as pro-innovation culture, effective institutions and regulatory environment. Moreover, seeking other ways to directly and indirectly contribute to HQED, for example, the digital economy, emerging industry cluster, industry synergy cluster, openness degree.

For the future research, it may also be important to construct the multidimensional evaluation of TI (including dimensions 
of TI input, TI output, TI environment and so on) and explore whether the conclusions in this study are supported. Additionally, a further step for the study is also interesting to test the findings are applicable to other urban belts and regions in China or other developing countries. Finally, with the increasing attention to green innovation, conducting the analysis on green patents on HQED may also be of great significance.

\section{ACKNOWLEDGMENT}

This work is supported by the Philosophy and Social Sciences Program Youth Project in Anhui Province of China, " Measurement, comparison and strategic path of high-quality green development in Anhui Province under the integration strategy of Yangtze River Delta" (Grant No.: AHSKQ2020D31).

\section{REFERENCES}

[1] Lin, T.C. (2003). Education, technical progress, and economic growth: The case of Taiwan. Economics of Education Review, 22(2): 213-220. https://doi.org/10.1016/S0272-7757(02)00030-4

[2] Agbola, F.W. (2014). Modelling the impact of foreign direct investment and human capital on economic growth: empirical evidence from the Philippines. Journal of the Asia Pacific Economy, 19(2): 272-289. https://doi.org/10.1080/13547860.2014.880282

[3] Woo, Y., Kim, E., Lim, J. (2017). The impact of education and R\&D investment on regional economic $\begin{array}{llll}\text { growth. } & \text { Sustainability, } & 976 \text { ) }\end{array}$ https://doi.org/10.3390/su9050676

[4] Chen, H., Liang, M. (2020). Empirical analysis on regional economic growth from the perspectives of entrepreneurship and investment in research and development. International Journal of Sustainable Development and Planning, 15(8): 1259-1265. https://doi.org/10.18280/ijsdp.150812

[5] Li, W., Yi, P. (2020). Assessment of city sustainabilitycoupling coordinated development among economy, society and environment. Journal of Cleaner Production, 256: 120453. https://doi.org/10.1016/j.jclepro.2020.120453

[6] Liu, S., Hou, P., Gao, Y., Tan, Y. (2020). Innovation and green total factor productivity in China: A linear and nonlinear investigation. Environmental Science and Pollution Research, 1-22. https://doi.org/10.1007/s11356-020-11436-1

[7] Wu, M., Wang, X., Chen, X., Cao, Y. (2020). The threshold effect of $R \& D$ investment on regional economic performance in China considering environmental regulation. Technology Analysis \& Strategic Management, 32(7): 851-868. https://doi.org/10.1080/09537325.2020.1715362

[8] Xu, H., Qiu, L., Liu, B., Liu, B., Wang, H., Lin, W. (2021). Does regional planning policy of Yangtze River Delta improve green technology innovation? Evidence from a quasi-natural experiment in China. Environmental Science and Pollution Research, 28(44): 62321-62337. https://doi.org/10.1007/S11356021-14946-8

[9] Hu, C., Jiang, H. (2021). Causal nexus between Sci-Tech talent and economic growth in the Pan-Yangtze River Delta of China. Sustainability, 13(12): 6707. https://doi.org/10.3390/SU13126707

[10] Fan, J., Zhang, Q., Luo, C. (2018). The evolution trend and countermeasures of the economic development quality of the Yangtze River Delta urban agglomeration. Industrial Technology Economy, 37(12): 70-77.

[11] Yang, R., Miao, X., Wong, C.W.Y., Wang, T., Du, M.J. (2021). Assessment on the interaction between technology innovation and eco-environmental systems in China. Environmental Science and Pollution Research, 28: 63127-63149. https://doi.org/10.1007/S11356-02115149-X

[12] Cheng, C., Ren, X.H., Dong, K.Y., Dong, X.C., Wang, Z. (2021). How does technological innovation mitigate $\mathrm{CO} 2$ emissions in OECD countries? Heterogeneous analysis using panel quantile regression. Journal of Environmental Management, 280: 111818. https://doi.org/10.1016/J.JENVMAN.2020.111818

[13] Su, Y., An, X.L. (2018). Application of threshold regression analysis to study the impact of regional technological innovation level on sustainable development. Renewable and Sustainable Energy Reviews, 89:

27-32. https://doi.org/10.1016/j.rser.2018.03.005

[14] Kong, Q., Peng, D., Ni, Y., Jiang, X., Wang, Z. (2021). Trade openness and economic growth quality of China: Empirical analysis using ARDL model. Finance Research Letters, 101488. https://doi.org/10.1016/j.frl.2020.101488

[15] Pan, X., Cheng, W., Gao, Y., Balezentis, T., Shen, Z. (2021). Is environmental regulation effective in promoting the quantity and quality of green innovation? Environmental Science and Pollution Research, 28(5): 6232-6241. https://doi.org/10.1007/s11356-020-10984$\mathrm{W}$

[16] Männasoo, K., Hein, H., Ruubel, R. (2018). The contributions of human capital, $\mathrm{R} \& \mathrm{D}$ spending and convergence to total factor productivity growth. Regional Studies, 52(12): 1598-1611. https://doi.org/10.1080/00343404.2018.1445848

[17] Gao, Y., Zhang, M., Zheng, J. (2021). Accounting and determinants analysis of China's provincial total factor productivity considering carbon emissions. China Economic Review, 65: 101576. https://doi.org/10.1016/J.CHIECO.2020.101576

[18] Liu, Y., Liu, M., Wang, G., Zhao, L., An, P. (2021). Effect of environmental regulation on high-quality economic development in China-An empirical analysis based on dynamic spatial Durbin model. Environmental Science and Pollution Research, 28: 54661-54678. https://doi.org/10.1007/s11356-021-13780-2

[19] Li, D., Hu, S. (2021). How does technological innovation mediate the relationship between environmental regulation and high-quality economic development? Empirical evidence from China. Sustainability, 13(4): 2231. https://doi.org/10.3390/su13042231

[20] Gu, W., Wang, J., Hua, X., Liu, Z. (2021). Entrepreneurship and high-quality economic development: based on the triple bottom line of sustainable development. International Entrepreneurship and Management Journal, 17(1): 1-27. https://doi.org/10.1007/s11365-020-00684-9

[21] Du, J., Zhang, J., Li, X. (2020). What is the mechanism 
of resource dependence and high-quality economic development? An empirical test from China. Sustainability, $\quad$ 12(19): 8144. https://doi.org/10.3390/su12198144

[22] Chen, Y., Zhu, M., Lu, J., Zhou, Q., Ma, W. (2020). Evaluation of ecological city and analysis of obstacle factors under the background of high-quality development: Taking cities in the Yellow River Basin as examples. Ecological Indicators, 118: 106771. https://doi.org/10.1016/j.ecolind.2020.106771

[23] Sun, X., Fang, S., Zhang, S. (2021). High-quality economic development in Huaihe economic zone level measurement and evaluation. Journal of Mathematics, 2021: 6615884. https://doi.org/10.1155/2021/6615884

[24] Li, X., Lu, Y., Huang, R. (2021). Whether foreign direct investment can promote high-quality economic development under environmental regulation: evidence from the Yangtze River Economic Belt, China. Environmental Science and Pollution Research, 28(17): 21674-21683. https://doi.org/10.1007/S11356-020$12032-Z$

[25] Liu, Y. (2020). Research on fiscal expenditure structure and high-quality economic development: An empirical study based on panel data from Chinese provinces from 2007 to 2017. American Journal of Industrial and Business Management, 10(2): 232-249. https://doi.org/10.4236/ajibm.2020.102015

[26] Zhang, J.K., Hou, Y.Z., Liu, P.L., He, J., Zhuo, X. (2019). Goal requirements and strategic path for high quality development. Management World, 7: 1-7. https://doi.org/10.19744/j.cnki.11-1235/f.20190711.001

[27] Yu, C., Wang, X., Sun, G. (2020). Digital finance and the quality of China's economic growth: Internal Mechanism and empirical evidence. Exploration of Economic Issues, 7: 1-14.

[28] Doraszelski, U., Jaumandreu, J. (2013). R\&D and productivity: Estimating endogenous productivity. Review of Economic Studies, 80(4): 1338-1383. https://doi.org/10.1093/restud/rdt011

[29] Baumann, J., Kritikos, A.S. (2016). The link between $\mathrm{R} \& \mathrm{D}$, innovation and productivity: Are micro firms different? Research Policy, 45(6): 1263-1274. https://doi.org/10.1016/j.respol.2016.03.008

[30] Li, X. (2009). China's regional innovation capacity in transition: An empirical approach. Research Policy, 38(2): 338-357. https://doi.org/10.1016/j.respol.2008.12.002

[31] Lopez-Rodriguez, J., Martinez-Lopez, D. (2017). Looking beyond the R\&D effects on innovation: The contribution of non-R\&D activities to total factor productivity growth in the EU. Structural Change and Economic Dynamics, 40: 37-45. https://doi.org/10.1016/j.strueco.2016.11.002

[32] Jia, H.W., Zhang, W.T., Pan, Y. (2021). Scientific and technological innovation, industrial structure upgrading and high-quality economic development. Shanghai Economic Research, 5: 50-60. https://doi.org/10.19626/j.cnki.cn31-1163/f.2021.05.006

[33] Jiang, Y.M., Meng, Q.C., Li, X. (2021). Performance evaluation of regional scientific and technological innovation driving high quality economic development. Statistics and Decision, 37(16): 76-80. https://doi.org/10.13546/j.cnki.tjyjc.2021.16.016

[34] Liu, H. (2019). The communication and European Regional economic growth: The interactive fixed effects approach. Economic Modelling, 83: 299-311. https://doi.org/10.1016/j.econmod.2019.07.016

[35] Feng, G., Peng, B., Su, L., Yang, T.T. (2019). Semiparametric single-index panel data models with interactive fixed effects: Theory and practice. Journal of Econometrics, 212(2): 607-622. https://doi.org/10.1016/j.jeconom.2019.05.018

[36] Bui, Q., Wang, Z., Zhang, B., Le, H.P., Vu, K.D. (2021). Revisiting the biomass energy-economic growth linkage of BRICS countries: A panel quantile regression with fixed effects approach. Journal of Cleaner Production, 316: 128382 . https://doi.org/10.1016/J.JCLEPRO.2021.128382

[37] Bai, J. (2009). Panel data models with interactive fixed effects. Econometrica, 77(4): 1229-1279. https://doi.org/10.3982/ECTA6135

[38] Asongu, S.A., Nnanna, J., Acha-Anyi, P.N. (2021). The openness hypothesis in the context of economic development in Sub-Saharan Africa: The moderating role of trade dynamics on FDI. The International Trade Journal, 35(4): 336-359. https://doi.org/10.1080/08853908.2020.1805376

[39] Feng, Y., Wang, X., Liang, Z. (2021). How does environmental information disclosure affect economic development and haze pollution in Chinese cities? The mediating role of green technology innovation. Science of the Total Environment, 775: 145811. https://doi.org/10.1016/J.SCITOTENV.2021.145811

[40] Shiyi, C.H.E.N., Dengke, C. (2018). Smog pollution, government governance and high-quality economic development. Economic Research, 53(2): 20-34.

[41] Miao, J.W., Feng, H. (2021). Does the agglomeration effect promote regional high-quality development? A case study of the Yangtze River Delta urban agglomeration. Exploration of Economic Issues, 2: 100110.

[42] Wang, D., Jiang, D., Fu, J., Lin, G., Zhang, J. (2020). Comprehensive assessment of production-livingecological space based on the coupling coordination degree model. Sustainability, 12(5): 2009. https://doi.org/10.3390/su12052009

[43] Ye, J. (2010). Multicriteria fuzzy decision-making method using entropy weights-based correlation coefficients of interval-valued intuitionistic fuzzy sets. Applied Mathematical Modelling, 34(12): 3864-3870. https://doi.org/10.1016/j.apm.2010.03.025

[44] Hoechle, D. (2007). Robust standard errors for panel regressions with cross-sectional dependence. The Stata Journal, 7(3): 281-312. https://doi.org/10.1177/1536867X0700700301

[45] Démurger, S. (2001). Infrastructure development and economic growth: An explanation for regional disparities in China? Journal of Comparative Economics, 29(1): 95117. https://doi.org/10.1006/jcec.2000.16 